\title{
Stress management for mantra techniques
}

\begin{abstract}
In this review article the author argues that complete presentation of various Indian cultural methods can reduce the stress and related mental and physical illnesses like Stress anxiety, depression etc. Life is neither possible to overcome safely. Indian cultural methods are increasing in Physical and mental health and reducing stress is an important stimulus of human growth and creativity as well an inevitable part of life.
\end{abstract}

Keywords: meditation, mantra, mudra, osteoporosis, post-traumatic stress disorder

\author{
Volume 2 Issue 2 - 2017
}

\author{
Balaji Deekshitulu PV \\ Department of Psychologist \& Alternative Medicine, Sri Balaji \\ Clinic, India
}

Correspondence: Balaji Deekshitulu PV, Department of Psychologist \& Alternative Medicine (Homeopathy), Sri Balaji Clinic, India, Tel 8885391722, 7207255557, Email drsribalaji@gmail.com

Received: December 14, 2016 | Published: April II, 2017

\section{Introduction}

Stress has reached epidemic proportions due to our fast-paced lifestyle and the consequent excessive demands on our bodies. Its can affects your physical and mental health. Chronic stress can increase your risk for gastric ulcers, osteoporosis and sexual dysfunction. It is linked to other physical illnesses including hypertension, heart disease, diabetes, asthma and arthritis. Chronic stress can also impair the immune system, leading to an increase in infections and worsening of skin conditions such as eczema. Stress hormones have also been associated with post-traumatic stress disorder (PTSD), substance abuse and mood disorders as well as anxiety.

\section{Causes in modern life}

Family Problems, Finance Problems, Tight Deadlines, Political Pressures, Poor Working Environment, Harassments, Discriminations, Long hours, High workloads, Changes to duties, Poor relations with colleges and family members etc.

\section{Signs}

Tiredness and irritability, Reduced quality work, Inductiveness and poor judgement, Lose of sense of humour, Physical illness such as headaches, nausea, aches and pains, Seeming jumpy or ill-at-ease, or admitting to sleeping badly, Increased sick leave, Poor time keeping, Changes working day patterns, Increased arguments and disputes between staff, General absenteeism, An increase in grievances and complaints, Greater staff turnover

\section{Management for vedic techniques}

a. Yoga

b. Meditation

c. Chanting Mantras

Wolf ${ }^{1}$ supported that the hypothesis ranging from .21 to .33 . The author suggests that the maha mantra has potential for utilization in clinical areas similar to those where other interventions of Eastern origin have been successful, such as treatment of stress, depression and addictions. Michael et al. ${ }^{2}$ discussed that the Mantra meditation is particularly focused upon. Anger management is also discussed, including the physical symptoms of anger, awareness of response patterns and power dynamics and options for expressing anger. Ajay Anil Gurjar, Siddharth A Ladhake study that the mental stress of a person gets reduced while the mind reaches steadiness. As a final point, we have confirmed scientifically the accomplishments of OM chanting in reducing the stress from the human mind.

Jawharali et al. ${ }^{3}$ study that the stress management. Mantra repetition involves frequent repetition throughout the day and night. To experience maximal benefit, mantra should be repeated silently everyday while walking, waiting or falling in asleep etc. Meditation is often considered to be an alternative and complementary medicine which can be used to treat peoples with stress-related mental and physical disorders. In this paper we review some of the studies conducted on effectiveness of mantras as stress buster.

Bormann ${ }^{4}$ about that the better results you'll notice. Build the mental muscle of your mind. Anita et al..$^{5}$ study that the rested mind that the entire beneficial cycle starts. In Psychoanalytical language meditation helps in conquering the neurotic tendencies and makes the mind peaceful and happy. Chanting of $\mathrm{OM}$ and Gayatri mantra stimulates the brain cells resulting in their activation and ultimately leading to better concentration. Alpna et al. ${ }^{6}$ suggested that the present study was made to study the effect of mantra chanting and gender on stress coping strategies. Malhotra et al. ${ }^{7}$ suggested that the Listening to music at work area reduces distractions, helps increase concentration and delays fatigue. It can be used to heal tinnitus as an educational tool to develop children with special needs Alzheimer's disease to improve motor skills in Parkinsonism and help alleviate pain after surgery. Deekshitulu ${ }^{8}$ revived that the Mantra therapy can be control of stress, depression, anxiety, fear and promotion of mental health and happiness. Studies have shown that Mantras can have beneficial effects on the health of the body as well as positive results in Mental \& Physical levels.

\section{Chanting}

i. Rhythmic speaking or singing, It makes use of deep breathing filling us with fresh air.

ii. Rhythmic tapping of tongue against certain points along the roof of our mouth, sends signals to hypothalamus. It regulates chemical activity and secretion of 'feel good' brain neurotransmitters like endorphins. These are sent into all parts of the body. 
iii. Being natural opiates they leave us happy, relaxed and recharged with positivity.

\section{Breathing}

i. Breath is a kind of barometer of the subtle energies of body and mind.

ii. Deep and Relaxed Breathing maintain an 'empty lung' position while exhaling and 'full lung' while inhaling.

iii. Kapal battifor cleansing breath.

iv. Anulom Vilom for alternate nostril breathing.

\section{Rhythm}

i. When we repeat the mantra with a regular flow the benefit is many folds. Patterns of sound are inscribed in brain and evoke emotional and brain energy. In brain low frequency waves set in and we relax........

ii. When we inhale while chanting from the mooladhara chakra, the two flows through all the seven chakra and PRANA/ Life flows in.......

\section{Mantras}

a. Is a brain stabilizer?

b. Improves concentration and steadiness.

c. It combines sound, breadth and rhythm.

d. It is a pleasure.

e. Perform it with positivity, cheerfulness, honesty.

f. As a result of the sound and vibrations, different patterns of the mind re arrange themselves to become tranquil.

g. Regular chanting helps in taking you to a spiritual journey where mind, body and soul become calm.

h. The mantra carries power through your body and you get rejuvenated.

\section{How to do?}

a. Sit down cross legged on the asana in the morning with back straight and upright neck and head.

b. It is your personal appointment with god so keep everything aside.

c. Sweep away your worries and thoughts.

d. Concentrate, check mental chattering and relax. e. Produce positive energy by rubbing your hands.

f. Open your third eye, smile and Chant.

\section{Conclusion}

Our attentiveness and our concentration are pilfered by the events around us. Different challenges and impediments have been faced by the humans due to their occupational activities. Meditation is essential for the human beings to come out of the above troubles. OM is a spiritual mantra, important to obtain peace and calm. Consciousness has been improved by the repetition of OM mantra. In this work, we have confirmed the significance of OM chanting. The time-frequency analysis has been carried out using wavelet transforms for the divine sound OM. We have concluded that OM chanting affords steadiness in the mind scientifically. This provides calm and peace too to the stressed mind. The mental stress of a person gets reduced while the mind reaches steadiness. As a final point, we have confirmed scientifically the accomplishments of OM chanting in reducing the stress from the human mind.

\section{Acknowledgements}

None.

\section{Conflict of interest}

The author declares no conflict of interest.

\section{References}

1. Wolf DB. Effects of the Hare Krishna Maha mantra on stress, depression and the three gunas. USA: Florida State University; 1999. 558 p.

2. Michael HA, Ironson G, Neil S. Anger Management/Mantra Meditation. UK: Oxford University Press; 2008. 99 p.

3. Jawharali BS, Hema CR (2013) Effectiveness of mantra as stress buster. KARPAGAM Journal of Computer Science 7(4).

4. Bormann J. A "Burnout Prevention" Tool for Improving Healthcare Providers' Health and Wellbeing: Mantram Repetition. VA San Diego Healthcare System, USA: 2013.

5. Anita S, Singh R. Educational stress in adolescents: chanting mantras as a powerful coping strategy. GJHSS. 2014;14(1).

6. Alpna A, Anshu A. Impact of mantra chanting on stress coping. IJPP. 2013;4(1):96-98.

7. Malhotra V, Garg R, Dhar U, et al. Mantra, music and reaction times IJMRHS. 2014;3(4):825-828.

8. Deekshitulu BPV. Role of mantras in mental health. IJAYUSH. 2015;1(6):34-38. 